\title{
Hernández y Ascasubi
}

El estudio de las relaciones entre el Martín Fierro y la obra de Ascasubi parece agotado. Todos los que trataron el asunto - de una $\mathfrak{u}$ otra manera- han afirmado que el autor gauchesco que más influyó en Hernández, o aquel que es su precedente inmediato más importante, es Ascasubi. Las diferencias comienzan cuando se trata de precisar en qué consiste ese influjo o esa precedencia. Los críticos pueden agruparse en tres tipos. Unos, como Lugones, Holmes, Rojas, Borges, Martínez Estrada, Battistessa, consideran que las diferencias estilísticas son tan grandes que resulta superfluo pensar que Aniceto el Gallo pueda haber prestado a Hernández nada concreto, fuera de la precedencia en tocar temas comunes de la literatura de frontera. ${ }^{1}$

Otros, especialmente Tiscornia y Azeves, insisten con absoluta seguridad en que el autor de Martín Fierro no solamente se inspiró en pasajes determinados de la obra ascasubiana, sino que de ella tomó temas, desarrollos, fórmulas lingüísticas, numerosos versos completos y que es Ascasubi quien más influyó en el Poema. ${ }^{2}$

1 Leopoldo Lugones, El Payador (Bs. As., Centurión, 1961), pp. 220-221. Ricardo Rojas, Historia de la literatura argentina (Bs. As., Kraft, 1957), II, 491. Henry A. Holmes, Martin Fierro; An Epic of the Argentine (New York, Instituto de las Españas, 1923), pp. 42-48. Jorge Luis Borges, Discusión (Bs. As., Emecé, 1957), pp. 15-17; en p. 15, hablando sobre Ascasubi como predecesor de Hernández, Borges escribe: "La segunda, la de premonición o aviso del Martín Fierro, es una insensatez: es accidental el parecido de las dos obras, nulo el de sus propósitos".

Ezequiel Martínez Estrada, Muerte y Transfiguración de Martín Fierro (México, F.C.E., 1948), II, 249-346; en p. 271, escribe: "El estilo del Martín Fierro difiere muchísimo más de Ascasubi que de ninguno de los otros poetas gauches$\cos ^{\prime}$. Y hablando de los poemas gauchescos, p. 265: "La influencia que ejercen en el Autor los poemas gauchescos es enorme, en el sentido de que contienen la casi totalidad de los temas de su Obra; pero en la elaboración es tan grande su originalidad, que el parentesco se reduce casi a lo estrictamente filogénico".

Angel J' Battistessa, "José Hernández" en Historia de la literatura argéntina (Bs. As., Peuser, 1959), III, p. 231, escribe: "Nada hay en Hernåndez que recuerde la desbocada parlería de Ascasubi".

2 Martín Fierro, ed. Tiscornia (Madrid, Aguilar, 1972), véanse especialmente las notas a los versos 3-6, 395, 567, 597, 773-774, 954, 1456-62, 1475-80, 1578, 1703, 2211-14, de la Ida; y 1971-81, 2154, 2451-52, 4301-02, de la Vuelta. Angel 
Emilio Carilla, finalmente, acepta el influjo de uno sobre el otro, pero aconseja prudencia en numerosas atribuciones de esa deuda apuntada por Tiscornia, acotando que en muchos casos hay evidentes exageraciones del docto editor de $1925 .^{3}$

Estas páginas pretenden un reexamen más riguroso de ese problema colocándolo en sus límites justos. $Y$ para comenzar, tratemos de responder a una pregunta fundamental: ¿qué pudo leer Hernández antes de terminar la Ida? Y esto nos lleva a fijar, en primer lugar, la fecha de entrega a los editores. Tres testimonios pueden ser aquí aducidos y ellos permiten con bastante seguridad datar el mes en que el modesto folleto ha entrado en máquinas. El más antiguo es una carta a su mujer, Carolina González del Solar, del 26 de octubre de 1872:

no obstante todo esto. . me ocupo de hacer imprimir en este momento mi libro Marín Fierro que debe salir pronto a volar.4

El otro es el aviso que, en el diario La República, del día 28 de noviembre de ese año, anunciaba la pronta aparición del poema. En ese suelto por primera vez aparecía en letras de molde el nombre del protagonista.5 El último es un detalle cronológico que puede extraerse del folleto mismo, en el cual se reproducía parte de un artículo de $L a$ Nación fechado el 14 de noviembre de 1872. Parece seguro que este texto fue extraído del diario cuando el folleto ya estaba en vías de impresión, y se agregó (como ocurrió con los otros que acompañaban al poema) para aumentar su volumen y encarecer los aspectos políticos y sociales del libro. ${ }^{6}$

Un examen objetivo de estos testimonios permite asentar esta conje-

H. Azeves, La elaboración literaria del Martín Fierro, (La Plata, Facultad de Humanidades y Ciencias de la Educación, 1960), pp. 21-27 y del mismo autor, Con el Martin Fierro (Bs. As., Remitido, 1968), pp. 27-28.

3 Martín Fierro, edición, prólogo y notas de Emilio Carilla (Barcelona, Labor, 1972), pp. 27-28; en n. 23 de la última página citada el comentarista acota: "En este sentido, si bien el estudio más detallado de las relaciones entre las obras de Ascasubi y Hernández lo ha realizado E. F. Tiscornia, conviene desechar, como exageradas, algunas derivaciones que el crítico apunta".

4 Horacio Zorraquín Becú, Tiempo y vida de José Hernández $1834-1886$ (Bs. As., Emecé, 1972), p. 205, n. 16.

's "Muy pronto saldrá á luz un folleto en versos gauchos, con el título de Martín Fierro, escrito por el Sr. D. José Hernández. Eentendemos que el gaucho Martín Fierro canta en su estilo nacional, sus aventuras, desdichas y tribulaciones de su vida nómade y del soldado en la frontera", op. cit. de Zorraquín Becú, p. 199. El aviso documenta que quien lo redactó había leído el Poema, y que éste ya debía estar terminado.

6 Véase lo que decimos en El poema Martín Fierro (Mendoza, Instituto de Cụltura Hispánica, 1972), pp. 28-29. 
tura: la Ida ya estaba terminada a mediados de octubre del 72 , entre el 15 y el 30 de octubre a más tardar.

$\mathrm{Y}$ ahora otra pregunta importante: ¿cuándo llegan a Buenos Aires los primeros ejemplates de las obras completas de Ascasubi que Dupont había impreso regiamente en París, en tres hermosos volúmenes? La lectura de los prólogos y colofones de la edición francesa del Santos Vega permite algunas deducciones seguras. La dedicatoria, a D. Jorge Atucha, está fechada el 2 de agosto. Al final del libro, después de las Erratas, Ascasubi señala que "Después de impreso este volumen "se ha enterado de la muerte de su íntimo amigo ocurrida el 6 de julio de ese año. La impresión de esa hoja agregada al final del volumen, debió retrasar por lo menos diez días la terminación del trabajo de la imprenta. Agréguense otros cinco o diez días para la encuadernación y ya nos encontramos a fines de agosto o comienzos de septiembre. Los primeros ejemplares debieron embarcar en los días iniciales de este último mes, digamos el cinco o el 8 de septiembre. Hoy sabemos que hacia 1860 un viaje en barco desde Buenos Aires hasta Burdeos, y después en tren desde alli hasta París demoraba en total unos cuarentas días. ${ }^{7}$ Suponemos que en esos diez años el plazo no debió acortarse demasiado. De todo esto podemos extraer una conclusión que parece lógica: los primeros ejemplates de las obras de Ascasubi en la edición Dupont no estuvieron en Buenos Aires antes del 8 o el 12 de octubre de ese año. $Y$ este cálculo se ve confirmado porque la primera noticia periodística que comentaba en la ciudad porteña la edición parisiense, aparece en la prensa a mediados de ese mes y según Mujica Láinez fue escrita por Héctor $F$. Varela. $^{8}$

Parece difícil que Hernández (enemigo político y literario de Ascasubi) haya recibido de este último algún ejemplar de regalo. Por otra parte suponemos que los primeros ejemplares en venta no debieron estar en librerías antes de fines de octubre o comienzos de noviembre. ¿Tuvo tiempo Hernández de leerlos, dado su tamaño, su precio y el hecho de que era hombre muy ocupado...? ¿Pudo haberse tomado el trabajo de leer los quince mil versos del Santos Vega antes de enviar à la imprenta su poema? Creemos que no. Y creemos que de una buena vez debe desecharse como un imposible, después de este esquemático

7 Eduardo Jorge Bosco, en el "Indice cronológico de la biografía de Hilario Ascasubi, en Obras (Bs. As., El Angel Gulab, 1952), II, 92-93, documentó el viaje que Ascasubi realizó partiendo de Buenos Aires el 14 de noviembre de 1860, y que terminó en París el 24 de diciembre de ese año a las 21 horas...

8 Manuel Mujica Láinez, Vida de Aniceto el Gallo (Bs. As., Emecé, 1943), p. 191. Por Bosco, op. cit., p. 123, sabemos que se trató de un extenso artículo en siete capítulos aparecidos en El Americano, entre el 14 de octubre y el 30 de noviembre de 1872 . 
examen cronológico, la idea de que Hernández haya leído la obra de Ascasubi antes de terminar la Ida.

Hernández pudo haber leído entonces el Paulino Lucero y las composiciones de Aniceto el Gallo pero, sobre todo, conoció las dos entregas de la versión primitiva del Santos Vega que aparecieron en Montevideo, en 1850. La generosidad del erudito colega de la Universidad del Sur, el profesor Félix Weinberg, nos ha permitido disponer, en este trabajo, de un juego de pruebas de página de la obra en la que Weinberg ha rescatado del olvido la versión primera del extenso poema gauchesco. ${ }^{9}$ Su examen permite adelantar que, sin dudas, éste fue el texto en que Hernández pudo inspirarse para algunos pasajes de su obra, tanto en la primera como en la segunda parte de la misma.

Examinaremos a continuación algunos pasajes del Poema, aquéllos en que Tiscornia y después Azeves (que sigue al primero en casi todos los casos) han encontrado influjo evidente de Ascasubi. Comencemos con las invocaciones de la Ida (y hagamos la salvedad que es necesaria: esas invocaciones no aparecen en la versión de 1850). Un simple cotejo permitirá comprobar que Martínez Estrada tenía razón cuando afirmaba que ambas obras se inspiraban en una tradición anterior, la de los romances de ciego o los libros de cordel. Tiscornia y Azeves están concordes en que los versos 7-18 de la Ida se inspiraton en un pasaje de "Los payadores" del Paulino Luceno. Unos ejemplos mostrarán que los comienzos y hasta los finales de la Ida recogían "topoi" hispánicos de los siglos XVI, XVII y XVII. Estos ejemplos corresponden a un espigueo en una sola colección :10

Emperatriz de los cielos, Madre de Dios soberana, concede á mi entendimiento vuestro auxilio, vuestra gracia, para que pueda esplicar la crueldad mas inhumana;

(El Maltés de Madrid, p. 265)
A vos reina Soberana, madre de Dios pura y bella, pido alumbréis mis sentidos, para que mi torpe lengua pueda teferir la historia mas peregrina y. adversa

$$
\text { (D. Antonio Benavides, p. 71) }
$$

9 Félix Weinberg, La primera versión del "Santos Vega" de Ascasubi. Un texto gaucbesco desconocido, obra a punto de salit a luz, y que reproduce con prólogo y notas del historiador: Los Mellizos o Rasgos dramáticos dé la vida del gaucho en las campañas y praderas de la Repuiblica Argentina (Montevideo, Imprenta de la Caridad, 1850), 89 páginas. Quiero agradecer aquí al docto amigo y catedrático la posibilidad de contar con este texto.

10. Romances de ciegos (Madrid, Taurus, 1966), recopilación y estudio preliminar de Julio Caro Baroja. Señalamos la página y en varios casos el título de cada romance. 
atención noble auditorio

$$
\text { (p. 87) }
$$

A la celestial Princesa, Madre del divino Verbo, le pido me dé su gracia, porque sin ella no puedo mover mi rústica lengua, ni dar á entender al pueblo lo que sucedió en Marsella

(El Alarbe de Marsella. ., p. 220)

A la que es madre del Verbo, María Señora nuestra, le pido humilde postrado me de gracia con que pueda referir á mi auditorio la más infausta tragedia y el infortunado caso que sucedió a una doncella

(Doña Josefa Ramírez, p. 134)
Las tres divinas personas Padre, Hijo y Espíritu Santo, que son un Dios, una esencia, les pido humilde y postrado alumbren $\mathrm{mi}$ entendimiento, me dén su auxilio y amparo, para que pueda esplicar

(San Albano, p. 246)

Estos comienzos, convertidos en tópicos, son los que influyeron en Ascasubi y Hernández. Ambos los recogieron de esa tradición perdida hoy, que estaba viviente y actuante en los campos del litoral de mediados del siglo XIX. Pero no para allí ese influjo; también se había vuelto lugar común el final, el cierre de estos relatos en verso. Basten éstos, tomados de otro romance de ciego, en el que se usa la misma rima que en el de Hernández:

$Y$ ya con estas noticias

mi relación acabé,

por ser ciertas las conté Hasta aquí llega mi historia, todas las desgracias dichas todo es la verdad fija

(I, 2305-2308) (Lisardo el estudiante, p. 34)

En cuanto a ciertos motivos comunes, veremos que la confrontación de pasajes que para Tiscornia y Azeves documentan la copia de Ascasubi por Hernández, en nuestro cotejo demuestran el distinto (y hasta opues- 
to) tratamiento del mismo asunto. Un ejemplo puede ser el de la orientación por los pastos:

No hemos de perder el rumbo,

Los dos somos güena yunta;

El que es gaucho va ande apunta, Aunque inore ande se encuentra;

$\mathrm{Pa}$ el lao en que el sol se dentra

Dueblan los pastos la punta

(I, 2209-2214)

y acá, entre los pajonales, en una noche nublada y oscura, después de darles un par de guieltas a pie, que conteste o que señale a qué rumbo se entra el sol o el lado por donde nace...

como que cualquier paisano tan sólo con agacharse y medio tantiar las pajas secarronas, luego sabe que cuando las tuesta el sol, siempre cain al naciente, y no hay cómo equivocarse.

(Santos Vega, 4771-4787)

Aun sabiendo que el pasaje no está en la versión de 1850 y que Hernández no leyó la versión de 1872 antes de escribir la Ida, las diferencias son tan grandes que ellas solas demuestran que no hay influjo de uno en el otro. Mientras para Hernández los pastos quemados por el sol inclínanse hacia el poniente, para Ascasubi éstos se doblan hacia el naciente. Por otra parte en Hernández la indicación se inserta en un momento dramático y está cargada de sentido didáctico, como tantos otros pasajes del Poema. ${ }^{11}$ En Ascasubi nos encontramos con una demostración de lo que sabia un paisano, confrontado con lo que puede saber un hombre de la ciudad. ${ }^{12}$ Esto además de las diferencias estilístcias entre uno y otro, ya señaladas por Lugones, Holmes y Martínez Estrada.

El pasaje anterior está inserto en otro mayor de Ascasubi, que tanto Tiscornia como Azeves también señalaron como fuente de Hernández. Pongámoslos frente a frente:

11 Véase lo que sobre el didactismo en el Poema decimos en "Iectura de Martín Fierro (Vuelta, cantos VI-IX)", Revistit de Literatura Argentina e Iberoamericana, $\mathrm{n}^{\circ} 2$ (Mendoza, diciembre 1960), 31-48.

12 Sobre el fenómeno de heliotropismo hace algunas consideraciones interesantes Rodolfo Senet, en La psicología gaucbesca en el Martin Fieryo (Bs. As., Gleizer, 1927), p. 29. 
Aquí no valen dotores, Sólo vale la esperencia; Aquí verían su inocencia Esos que todo lo saben; Porque esto tiene otra llave $Y$ el gaucho tiene su cencia

(I, 1457-1462)
¡Que vengan facultativos en cencias, de todas clases, los más profundos! ¿Que vengan de Uropa y otras ciudades esos leidos y escrebidos, $y$ en ancas nuestros manates puebleros! ... no digo todos, pues todos no son iguales: hablo tan sólo de aquellos tan fantásticos, que no hacen caso de un pobre paisano, ....

Pues, bien; los sabios que explican la causa de casos tales y que por esa. razón piensan que todo lo saben, ya que son tan entendidos, que vengan a estos parajes y todas nuestras costumbres las miren bien y las palpen, 4760 y luego que nos expliquen de corrido, sin turbarse, la cencia de nuestras bolas y el poder de nuestros piales, para con un tiro a tiempo ...

(Santos Vega, 4724-4770; C.XXXII)

Hernández intenta defender la existencia de una sabiduría experiencial en el hombre de campo, de una forma de vivir $\mathrm{y}$ de actuar nacidas de lo cotidiano y de la naturaleza, legada oralmente de padres a hijos. $Y$ este saber es $\tan$ valioso y $\tan$ legítimo como el conocimiento científico en que vive el hombre urbano, porque le ha permitido al gaucho insertarse en esa naturaleza y vivir eficazmente en ella. Su tono es triste y condenatorio.

Ascasubi adopta una actitud casi de balandronada primitiva; parece hacer propaganda altanera dirigida a un público culto al que le interesa atraer por el color local, por lo pintoresco. Su tono es festivo y no hay condena hacia los cultos. Hasta en un momento se permite decir algo 
que sería inadmisible en Hernández. Como Ascasubi, en el fondo, pertenecía a ese mundo culto y no podía condenarlo totalmente, se cuida muy bien de acotar que no todos los hombres de la ciudad eran iguales, que también hay quienes saben apreciar esas habilidades campesinas (así se explican los versos $4730-4734$ que hacen esa 'diferencia entre los puebleros de una y otra clase...).

Ambos autores tocaron un tema semejante: el de la oposición entre el campo y la ciudad, antiguo y muy documentado. Ambos se inspiraron en un tópico frecuente, tanto en la gauchesca como en mucha de la literatura española anterior y coetánea: la sátira de los doctores, de los "puebleros" que con fatuidad se reían de los conocimientos primitivos del campesino. Pero en cada uno hay intenciones, tonos, sentidos, públicos, "situación" del que cantaba, totalmente distintos. Carilla, en nota de su edición citada, cree ver además en el pasaje hernandino referencias veladas y hostiles a muchas de las creaciones científicas de Sarmiento. Interpretación que parece aventurada ya que Hernández, cuando fue legislador, apoyó fervorosamente algunos proyectos parecidos a los de Sarmiento en cuanto a educación. ${ }^{13}$

Otro pasaje que no admite comparaciones por las notables diferencias en el argumento, el sentido, el tono y el estilo es el del largo Canto XII de la Vuelta, en el que el Hijo Mayor de Fierro narra su dolorosa vida de preso. Tiscornia es el único crítico que comentando en nota los versos 1971-1981 de la Vuelta escribe:

En estas estrofas, como en otros rasgos de las anteriores, la pintura de la vida carcelaria aparece influida por Ascasubi (Santos Vega, c. XXXIX y XL) que narra la reclusión de Luis, el criminal, las solícitas visitas de sus tutores, en especial de doña Estrella, y las debilidades del guardián Masramón para con el preso que habían de valerle, a la postre, morir asesinado a manos del mismo.

Los versos 1971-1981 dicen simplemente que otros presos recibian visitas en prisión, pero a él nadie lo visitaba. Resulta imposible ver en eso influencia ascasubiana. Pero hay más. El largo canto del Hijo Mayor es un treno, un doloroso lamento sobre la soledad, el silencio, la desventura absoluta del preso sin amigos, ni amantes, sin familia, sin dinero. $U_{\mathbf{n}}$ hombre que durante largo tiempo vive entre cuatro paredes silenciosas, abandonado de todos y por todos. Cientos de versos en los cuales

13 Algunos ejemplos de esos proyectos de leyes pueden lectse en nuestro libro próximo a aparecer, Hernández, poesia y politica (Bs. As., Plus Uitra), segunda parte: "El Legislador". 
(como señaló genialmente Martínez Estrada) no ocurre nada, sólo escuchamos la expresión de un alma hundida en el dolor por falta de libertad, de justicia, de calor humano, de alguien con quien dialogar, a quien entregar el alma. Una tremenda elegía sobre los bienes perdidos y el dolor de recordarlos y de reclamarlos.

En Ascasubi el pasaje sobre la prisión está inundado de brillo y de acción folletinesca, de aspectos picarescos en los relatos sobre las técnicas para escapar, de momentos de tensión en la huida de Luis (que éste prepara cuidadosamente), con personajes típicos que, si por una parte documentan la inmoralidad de la vida judicial y penitenciaria, por la otra persiguen la risotada inmediata, el chiste sucio o verde, lo aventurero de los libros de cordel o de los relatos versificados sobre bandidos. ${ }^{14}$

En cuanto a los versos que cita Tiscornia, hasta en su sentido difieren sustancialmente de una a otra obra: mientras al Hijo Mayor nadie lo visita, a Luis, el bandido, lo cuidan la madrastra y los guardias. Pero hay diferencias mayores. Mientras Ascasubi da del Alcalde de la prisión una imagen negativa, mostrándolo como un judío ávido de dinero y rapiña, el Hijo Mayor habla del Jefe de la cárcel como de un hombre bueno $\mathrm{y}$ caritativo (II, 2059-2060: "El hombre que manda allí/ Es poco menos que un santo").

$Y$ es que las intenciones eran distintas en ambos pasajes. Ascasubi se siente atraído por la acción, que no decae un solo instante, por lo novelesco y la contraposición folletinesca de tipos románticos caracterizados por una sola pasión: la sed de matar, la avidez de dinero, la gula, la inocencia zafia. La acción vertiginosa y cambiante por sobre toda otra consideración expresiva. Ascasubi es un novelista en verso, y un novelista romántico de tipo folletinesco que escribe para un público de muy bajo nivel cultural y estético. Y que no se preocupa en tocar otras fibras (ni otros temas) que aquellos que sabe de efecto seguro sobre ese público. Hernández expresa en trecientos setenta y siete versos la confesión dolorida y lírica de un alma que recuerda años vacíos de un pasado doloroso y tristísimo. $\mathrm{Y}$ junto a este período detenido donde la soledad y el silencio florecen como árboles negros, Hernández no quiere entretener ni divertir. Persigue, como en otros tantos momentos de su obra, la denuncia concreta: la terrible ferocidad de la vida carcelaria de la época queda documentada no en sus aspectos aventureros y hasta cómicos o tragicómicos (como hizo Ascasubi), sino en los más siniestros de desamparo y de crueldad inútil.

14 Sobre lo folletinesco y lo cómico en esta obra puede consultarse nuestro estudio, "Ascasubi: Santos Vega", Revista de Lite'raturas Modernas, no 10 (Mendoza, Facultad de Filosofía y Letras, 1971), pp. 77-111. 
VIDA DE LOS GAUCHOS EN EL EJÉRCITO

Este es uno de los pocos pasajes donde es aceptable reconocer que Hernández se inspiró en Ascasubi. Es evidente que la pintura de los gauchos en la milicia que aparece en pasajes de los cantos III, IV y V de la Ida, está inspirada en la segunda parte de la Carta de Donato Jurao que aparece en Aniceto el Gallo, como señalaron primero Tiscornia y ha demostrado fehacientemente después, Angel H. Azeves. ${ }^{15}$ Versos, palabras, expresiones, ideas generales, coinciden en ambos textos.

\section{LA MADRUGADA}

Azeves ha realizado un cotejo de los versos 151-190 de la Ida, con el Canto $\mathrm{X}$ de Santos Vega. Aquí solamente quisiéramos intentar ese cotejo con más cuidado y utilizando los versos de la versión de 1850. Su confrontación probará que Hernández había leído el pasaje, pero lo recrea con su característica maestría dinamizadora. Martínez Estrada también cotejó estos textos (op. cit., pp. 271-272), indicando que es éste uno de los contados momentos en que Ascasubi alcanza la concisión hernandina. Ya veremos que Hernández toma ideas más que versos concretos (seguimos la numeración de Weinberg en su edición citada):

Ascasubi

955 Venía clariando el cielo

La luz de la madrugada,

$Y$ las gallinas al vuelo

Se dejaban caer al suelo

De encima de la ramada.

$965 \mathrm{Y}$ como lumbre lejana

De radiante reverbero,

Alegrando el campo entero,

Nacía con la mañana

Hermosísimo el lucero.
Hernández

Apenas la ma'drugada

Empezaba á coloriar

Los pájaros á cantar,

$Y$ las gallinas á apiarse,

Era cosa de largarse

Cada cual á trabajar. (I, 151-156)

Entonces. . cuando el lucero

Brillaba en el cielo santo

$Y$ los gallos con su canto

Nos decían que el día llegaba,

A la cocina rumbiaba

El gaucho... que era un encanto.

$(I, 139-144)$

15 Ver nota de Tiscornia a versos 773-774 y Azeves, La elaboración literaria del $M, F$, pp, 22-23. 
995 Luz brillante que allí asoma El sol antes de nacer; $\mathrm{Y}$ entonces, da gozo el ver Los gauchos sobre la loma Al campear y recojer.

$1000 \mathrm{Y}$ se vían alegrones

Pot varios rumbos, cantando; $Y$ sus caballos saltando Fogozos los albardones Al galope y escarziando.
Este se ata las espuelas, Se sale el otro cantando, Uno busca un pellón blando, Este un lazo, otro un rebenque, $Y$ los pingos relinchando, Los llaman, dende el palenque.

(I, 157-162)

$Y$ mientras domaban unos, Otros al campo salían, Y la hacienda recogían, Las manadas repuntaban, $Y$ ansí sin sentir pasaban Entretenidos el día. (I, 187-192)

Compárese, además, v. 997 de Ascasubi, con I, 139 de Hernánidez. En estos otros textos ha habido una trasposición, pero Hernández pocas veces adopta la postura del espectador que describe desde afuera un escenario (como Ascasubi), sino dinamiza las acciones en el instante de realizarlas narrándolas con técnica presentativa:

$1040 \mathrm{Y}$ los potros relinchaban

Entre las lleguas mezclados, Y allá lejos encelados Los baguales contestaban Tódos desasosegados.

$1050 \mathrm{Al}$ concluir la recojida; Cuando entran á corretiarlos, $\mathrm{Y}$ que al tiempo de alcanzarlos, Aquellos, de una tendida, Se divierten en cociarlos.
Ande estaba el animal

Bufidos que se las pela...

$Y$, más malo que su agüela,

Se hacía astillas el bagual.

$$
\text { (I, 165-168) }
$$

$Y$ en las playas corcoviando

Pedazos se hacia el sotreta, Mientras él por las paletas

Le jugaba las lloronas,

$\mathrm{Y}$ al ruido de las caronas

Salía haciéndose gambetas. $(\mathrm{I}, 175.180)$

\section{LOS MALONES INDÍGENAS}

El primero en ejemplificar ataques indígenas con pasajes de Ascasubi y de Hernández fue Fred M. Page, quien tres años antes de terminar el siglo Xrx editó en Alemania la primera tesis doctoral dedicada al estudio de algunos aspectos de la poesía y el habla gauchesca del Río de la Pla- 
ta. ${ }^{16}$ Veintiséis años más tarde otro norteamericano, Holmes, comparó esos pasajes poniéndolos frente a frente (Santos Vega, 1331-1369 y Martín Fierro, I, canto III) y los acompañó de una airosa traducción al inglés. ${ }^{17}$ En 1948 Martínez Estrada llevó a cabo el estudio más detenido del tema indigena en el Poema -y el mejor hasta hoy realizadosugiriendo la cercanía con Ascasubi. Aquí se cotejarán pasajes de ambos autores no buscando influencias demasiado visibles, sino tratando de demostrar que Hernández siempre tuvo en cuenta el texto de la versión montevideana del Santos Veg® (seguimos la numeración en los versos propuesta por Weinberg):

820. A robar en las estancias

$Y$ matar sin compasión,

Quemando las poblaciones

$1354 \mathrm{Y}$ en media luna formaos

$1329 \mathrm{Y}$ envueltos en la manguiada

Vienen, perros cimarrones,

Zorros, Ávestruces, Liones,

Gamas, Liebres y Venaos,

1909 El campo todo cuajáo

De Gamas y de Avestruces,

$Y$ vichos de toda laya,

1351 Que al trote largo apuraos

$1389 \mathrm{Y}$ no entiende de clamores,

Porque ciegos atropellan,

$Y$ asi forzan y degüellan

Niños, ancianos y mozos

Pues como tigres rabiosos

En ferocidá descuellan.
Al indio, pues donde dentra

Roba y mata cuanto encuentra

$Y$ quema las poblaciones

$$
\text { (I, 478-480) }
$$

Caminan entre tinieblas

Con un cerco bien formao

Lo estrechan con gran cuidao

$\mathrm{Y}$ agarran, al aclarar,

Ñanduces, gamas, venaos,

Cuanto han podido dentrar

(II, 524-528)

Marcha el indio á trote largo,

Paso que rinde y que dura;

$$
\text { (II, 517-518) }
$$

Allí sí, se ven desgracias

$Y$ lágrimas y afliciones,

Naides le pida perdones

Al indio... etc. (I, 475-480)

No salvan de su juror

$\mathrm{Ni}$ a los pobres angelitos;

Viejos, mozos y chiquitos

\footnotetext{
16 Fred M. Page, The Descendants of the Juglares of Old Spain in La Plata, Dissertation (Darmstadt, G. Otto, 1897), pp. 39-42.

17 Holmes, op. cit., pp. 44-46. La confrontación a doble columna estaba precedida de estas consideraciones: "An examination of kindred passages dealing with Indian invasions and outlaw fights with police platoons, will show how differently Ascasubi and Hernández worked out the same commonplace themes of frontier life".
} 
Los mata del mesmo modo;

Que el indio lo arregla todo

Con la lanza y con los gritos.

$$
\text { (1, 481-486) }
$$

Odia de muerte al cristiano,

Hace guerra sin cuartel;

Para matar es sin yel,

Es fiero de condición;

No golpéa la compasión

En el pecho del infiel. (II, 553.8)

1425 En fin, a la retirada

No se van todos reunidos,

Porque marchan estendidos,

Por la campaña asolada:
Aquel desierto se agita

Cuando la invasión regresa;

Llevan miles de cabezas

De vacuno y yeguarizo:

Aquello es un hervidero

De pampas, un celemín,

Cuando riunen el botín

Juntando toda la hacienda,

Es cantidá tan tremenda

Que no alcanza á verse el fin.

(II, 607-618)

1409 Y luego á la repartida

1395 De-hai, borrachos, en con-

[tiendas...

Entran los más mozetones,

Para las reparticiones

De las cautivas y prendas:

$Y$ por fin, con las haciendas

1400 De todo el pago se arréan:

$Y$ cuando razas huméan

Las casas de los cristianos,

Los indios pampas ufanos

Para el desierto trotean.

1355 Desnudos del cuerpo entero,
Empiezan con todo empeño

A hacerse la repartija.

Se reparten el botín

Con igualdá, sin malicia;

Ninguna falta comete:

$$
\text { (II, 634-642) }
$$

No muestra el indio codicia,
En los caballos en pelo

Se vienen médio desnudos

(II, 485-486) 
$1363 \mathrm{Y}$ se pintan de manera

Que horrorizan de fierazos.

$\mathrm{Y}$ como écos del infierno

Tocan roncas y confusas

Entre un enjambre de chuzas

Varias trompetas de cuerno.
Viene á tierra de cristianos

Como furia del infierno.

(II, 627-628)

$Y$ el salvaje, como fiera

Disparada del infierno.

(II, 1331-1332)

Me parece estarlas viendo

Mas fieras que Satanás.

(II, 767-768)

\section{LA DEFORMACIÓN DE LOS NOMBRES Y LOS EUFEMISMOS}

No parece indispensable remitirse a Ascasubi para explicar el hecho de que Hernández deformara el nombre de Martin de Gaínza, llamándolo Don Ganza (I, 954). Ya habían hecho lo mismo Hidalgo, Pérez, Del Campo y era lugar común de toda la poesía gauchesca. ¿Por qué explicarlo como plagio de Ascasubi...? 'Tal vez sea más acertado decir que era uno de los tantos rasgos del género heredado por uno de sus cultores.

Otro tanto ocurre con los eufemismos en que se disfrazaban palabrotas muy hispánicas (por ej. I, 1578). No vemos razones para afirmar que Hernández las tomó de su predecesor; pudo haberlas escuchado directamente de fuentes orales donde eran (y son todavía hoy) muy usadas. Basta hablar con los habitantes de muchas zonas rurales de nuestro país para encontrarlas todvía vivas y eficaces.

\section{LOS PRÉSTAMOS LINGÜÍSTICOS}

Este tal vez sea el sector donde más difícil se hace aceptar que Hernández haya copiado de Ascasubi expresiones vivientes y comunes en la conversación de la gente del campo. Afirmar - como hacen Tiscornia y Azeves y repiten otros críticos- que Hernández tomó de su coetáneo formas entonces $\mathrm{y}$ hoy muy frecuentes en el habla cotidiana, no parece fácilmente demostrable. Aquí, como en casos anteriores, resulta mucho más prudente la sabia observación de Carilla cuando escribe: "Conviene andar aquí con cuidado y no considerar siempre como préstamo literario lo que, sin duda, pertenecía a un fondo vivo de la lengua gauchesca y que Hernández pudo recoger en ese fondo". ${ }^{18}$

18 Edición citada, p. 28. 
Hay algo además constante en todo el siglo XIX y todavía visible en el XX en nuestro país: la familiaridad de muchos hombres cultos, urbanos, viajeros impenitentes a Europa, con el habla campesina. Esos hombres que, como Mansilla o Cambaceres, mezclan sin solución de continuidad (y sin problema alguno) expresiones francesas o inglesas con fórmulas lingüísticas típicamente gauchas. Los casos de Güiraldes o de Lynch nos eximen de mayotes comentarios demostrativos. ¿Por qué Hernández debía aprender en Ascasubi expresiones que había escuchado desde niño en la casa paterna, en los campos y en las calles...?

Entre todas las expresiones que han sido señaladas como de fuente ascasubiana habría que hacer una división en dos grupos. Por una parte las formas lingüísticas cristalizadas, aquellas que han resistido el paso del tiempo y que no solamente aparecen en Ascasubi y Hernández, sino que están documentadas en otros autores gauchescos y -esto nos parece importante- todavía hoy persisten incorporadas a la lengua coloquial campesina, tanto del litoral como del interior argentino. En este grupo habría que colocar formas como: pitar del juerte (I, 395), las tres Marias (para hablar de las boleadoras, I, 597), bacerse el chancho rengo (I, 1703), gïey cometa (II, 2451-52). Estas expresiones debieron ser tomadas directamente del habla gauchesca.

Otro grupo lo constituirían aquellas expresiones circunstanciales que ya han desaparecido del habla rural, o que no usaton otros autores del género: echar panes (I, 567), como moro sin señor (II, 2154 y 2746). En estos casos deberáa suponerse el influjo de Ascasubi mientras no contemos con mayor documentación probatoria referida al siglo XIX.

Un caso especial, merecedor de un estudio detenido, lo constituye la forma dejarse cde como el carancbo (II, 4301-02). Tiscornia, sin documentación alguna, indica que la expresión significa entre los paisanos 'descolgarse de golpe y porrazo con preguntas muy arduas o con juicios pesados'. Ninguno de los anotadores o comentaristas del vocabulario del Poema da una explicación fundada de esta fórmula. Si nos referimos al sentido contextual del pasaje es evidente que Fierro, irónicamente y refiriéndose a la pregunta que acaba de hacerle el Moreno comenta (para los que escuchan más que para su interlocutor) tanto lo inesperado de la dificultad de la pregunta, como la agresividad que hay debajo de la capa de respeto y de educación que el Moreno muestra. Por una parte ha querido sorprenderlo (cayendo sobre él silenciosamente y a plomo, como hace el carancho); por otra atacarlo, vencerlo y despojarlo de su calidad de cantor (devorándosela como hace este animal con los despojos muertos de otros animales). Y a la vez, la ironía de Fierro encierra estos dos aspectos: a) no lo ha sorprendido aunque haya caído por sorpresa; 
b) no va a vencetlo ni a despojarlo de su calidad de cantor, esto es, no se va a dejar devorar como vaca muerta.

No vemos razones para explicar - como hace Azeves siguiendo a Tiscornia -esta expresión como inspirada por Ascasubi. ${ }^{19}$ El texto del Santos Vega que se aduce como fuente (2090-2120), solamente hace referencia a la manera de instalarse el carancho en el nido. Hernández se remite tanto a la caída silenciosa y a plomo, como a la avidez cárnea del animal, tradicional en nuestros campos y que todavía persiste en expresiones coloquiales. Becco, en su explicación de este pasaje, copia otro de Güiraldes que remite a esta segunda intención significativa en el texto hernandino. ${ }^{20}$

\title{
CONCLUSIONES
}

El examen realizado permite - creemos- ceñir con mucha mayor precisión la deuda de Hernández con Ascasubi. Es evidente que el primero conoció los poemas de Aniceto el Gallo, los trovos de Paulino Lucero y la obra que más influyó en Martín Fierro fue el Santos Vega, pero en su edición reducida de Montevideo, 1850. Esos textos sirvieron de inspiración para estas partes del poema hernandino: pasajes de los cantos III, IV y V de la Ida, sobre la vida en la milicia; la descripción de la madrugada en la primera parte; los malones indígenas tanto de la Ida como de la Vuelta.

En cuanto a los préstamos lingüísticos éstos deberán ser reducidos apenas a algunas contadas expresiones: echar panes, como moro sin señor.

Rodolfo A. Borello

\author{
Universidad Nacional de Cuyo \\ Mendoza. Argentina.
}

19 La elaboración literaria del M. F., p. 24; en la misma obra, p. 27, Azeves dice que Hernández toma de Ascasubi estas fórmulas: al ñudo, al botón, venir a pelo, clavar el pico, bacerse cargo, de mi flor, como un cielo, hacerse bumo, bacerse el cbiquito, bacérsele robo, llevar la media arroba, ir a la fija, bacerse el sarnoso, bacerse perdiz, cuerpo de güey, la mayoría de las cuales pudo haberlas tomado del habla rural o de otros autores; y muchas todavía usuales en el interior de nuestro país.

${ }_{20}$ Martín Fierro, Introducción, notas, bibliografía y vocabulario de Horacio Jorge Becco (Bs. As., Huemul, 1967), pp. 411-412, n $^{\circ} 487$. 